\title{
ASSESSMENT OF STRUCTURAL DAMAGE AND EVOLUTION IN TIME IN HISTORICAL CONSTRUCTIONS USING NUMERICAL MODELS: THE CASE OF THE CHURCH OF SAINT BASSIANO IN PIZZIGHETTONE, CREMONA
}

\author{
GRIGOR ANGJELIU ${ }^{1 *}$, GIULIANA CARDANI ${ }^{1}$ AND DARIO CORONELLI ${ }^{1}$ \\ ${ }^{1}$ Department of Civil and Environmental Engineering \\ Politecnico di Milano (POLIMI) \\ Piazza Leonardo da Vinci, 32, 20133 Milan, Italy \\ e-mail: grigor.angjeliu@polimi.it, www.polimi.it (*corresponding author) \\ email: \{giuliana.cardani, dario.coronelli\}@polimi.it, www.polimi.it
}

Keywords: Historical Structure, Masonry, Damage, Lidar survey, Structural evolution, FE model.

\begin{abstract}
This paper investigates the capability of advanced numerical modelling techniques to simulate experimental observations as damage or deformations in complex masonry structures. The case of the church of St. Bassiano in Pizzighettone, Cremona Italy is chosen.

A multidisciplinary research was set up to collect data as geometric survey with Lidar technology, measurement of axial force in the iron tie rods of the nave, and a monitoring system for crack widths. The data was used as an input to develop and validate a finite element model to study the structural damage and the evolution of the building in time.

The finite element model features a three-dimensional geometry, which is created in part automatically, taking advantage of a parametric model for ribbed masonry vaults, proposed recently by the authors. The FE model results in close adherence with the real building structure, due to the accuracy of the collected data. The simulation model features a continuum plastic damage model to take into consideration the masonry constitutive behaviour.

The results show how the system response is closely related to the structural evolution in time, associated with the dismantling of the chapels on the south side and the addition of the iron tie rods in the nave. The numerical simulations highlight also the important effect of the soil settlements in the present crack pattern. The information obtained using this approach will allow to understand the active mechanisms in the building and to optimise the technical interventions in critical parts of the structure.
\end{abstract}

\section{INTRODUCTION}

Changes, transformations and repairs that historical buildings have undergone over the centuries, leave indelible traces in their structure, often affecting the local or even global structural behaviour of the buildings. The actual performance is difficult to be understood and far from that designed at the time of its construction.

The value of architectural heritage is not only related to its aesthetic appearance, but also to 
the integrity of materials and structures, as a single product of a constructive technology of a specific historical period and place [1]. Preserving the material component is therefore closely connected with understating the causes of damage and designing compatible repair techniques.

Existing damage in the form of cracks or deformation, may originate from different causes, including: loads, actions, or construction phases which may not be present today [2]. Advanced numerical models are widely proposed in the literature to understand and explain observed damage, understand its evolution in time and design structural strengthening [3]. When considering the complexity of historical buildings, the accurate recording of their geometry and state of conservation are essential to build a structural model correctly representing its structural deficiencies. In this direction, technologies as Lidar scanning have made possible a fast documentation of buildings, in particular remote elements which are difficult to be surveyed manually e.g. vaults. Furthermore, Scan to BIM processes [4] or procedural modelling has made 3D solid models more accessible for FE simulations [5-7].

Particular attention has been lately dedicated to considering the structural evolution in time through the sequential analysis in continuum models. In the Basilica of St. Vitale in Ravenna the detailed 3D FE model was used to investigate the origin of the surveyed crack pattern and concluded that among the causes could be the transformations and repairs in time [8]. Among the first examples of sequential analysis combined with long-term effect analysis was considered in Mallorca Cathedral, to interpret the present damage and current deformations [9]. In Milan Cathedral a correlation was demonstrated between the construction process, settlements in time and the tension force in iron ties [10]
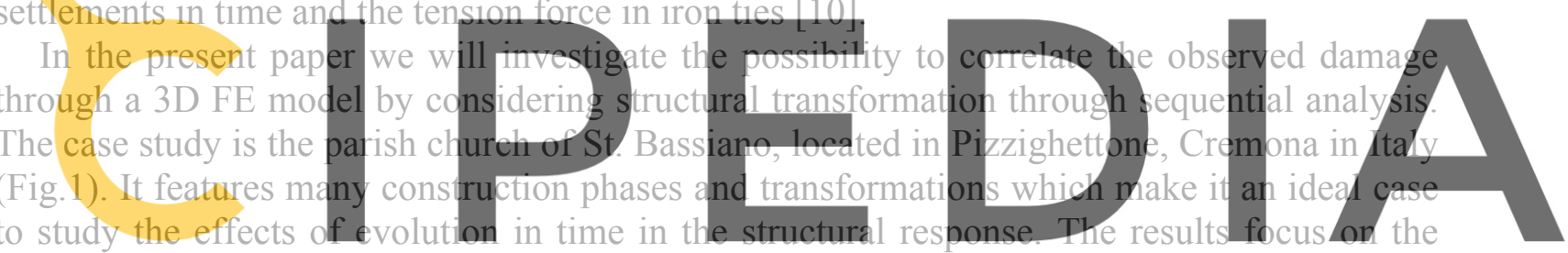

interpretation of the observed damage in relation to the removal of the southern chapels and the

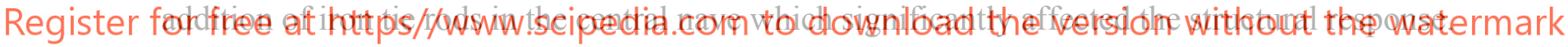
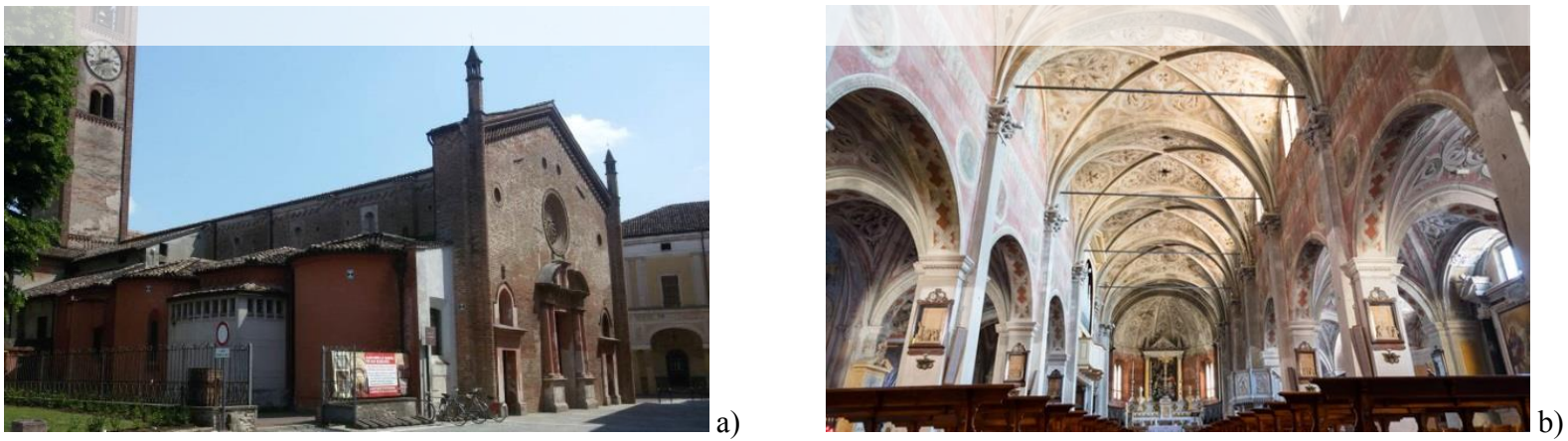

Figure 1: Saint Bassiano church: a) external and b) internal view.

\section{CASE STUDY}

\subsection{Overview}

The church of St. Bassiano was built in the $12^{\text {th }}$ century in Lombard-Romanesque style (Fig. 1) It is located in the center of Pizzighettone, a small city in Northern Italy called in Latin language 
Piceleo, along the Adda river. The church of St. Bassiano was closed for celebrations and access for visitors in 2012, as the damage observed in the structure increased seriously after the earthquake that hit Emilia Romagna region in 2012.

\subsection{Geometric survey}

A geometric survey was carried using a high-resolution LiDAR sensor (OS1-64). The configuration during the acquisition phase was set out to a horizontal resolution of 2048 points and a vertical resolution of 64 point at a rotation rate of $10 \mathrm{~Hz}$ (Fig. 2 - 3).

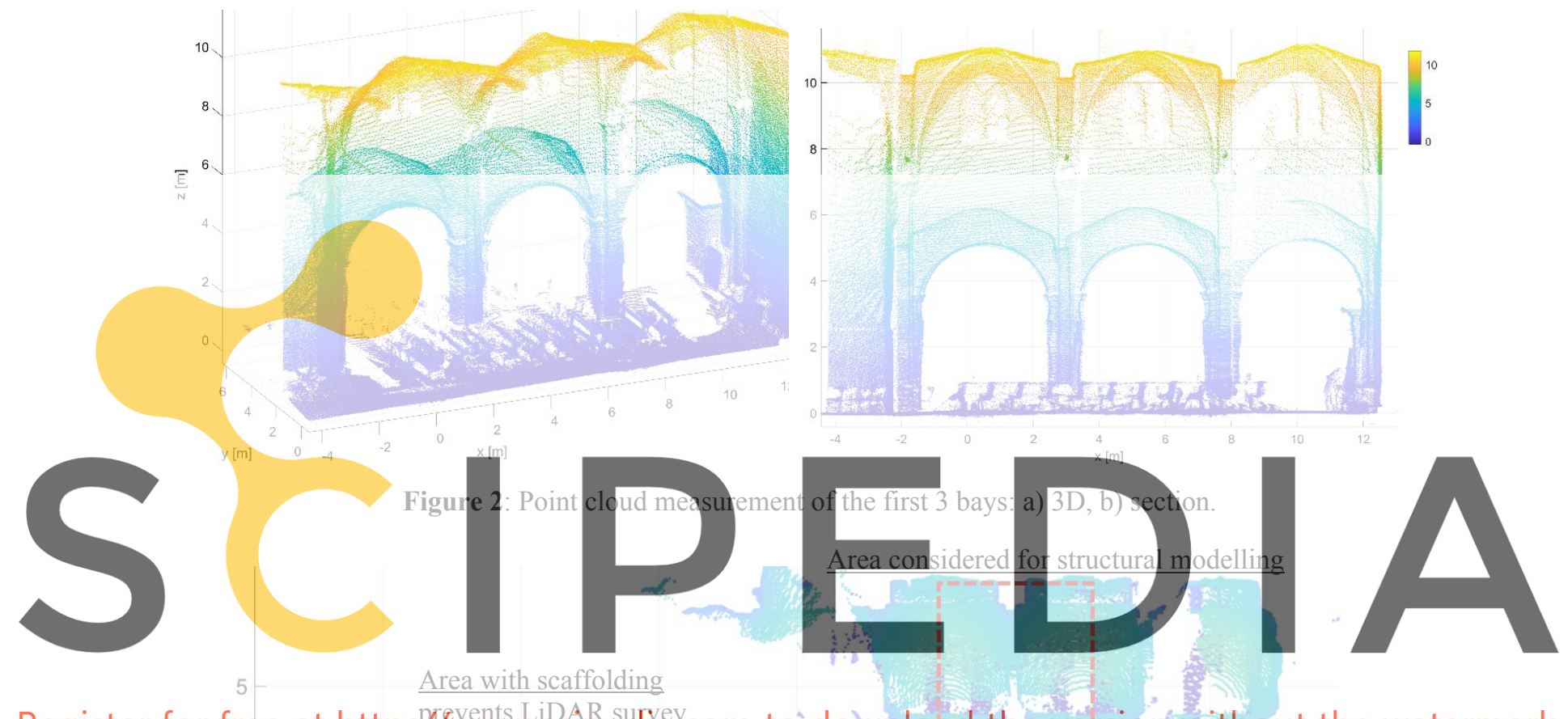

Register for free at https/wwww.scipedra.com to download the version without the watermark

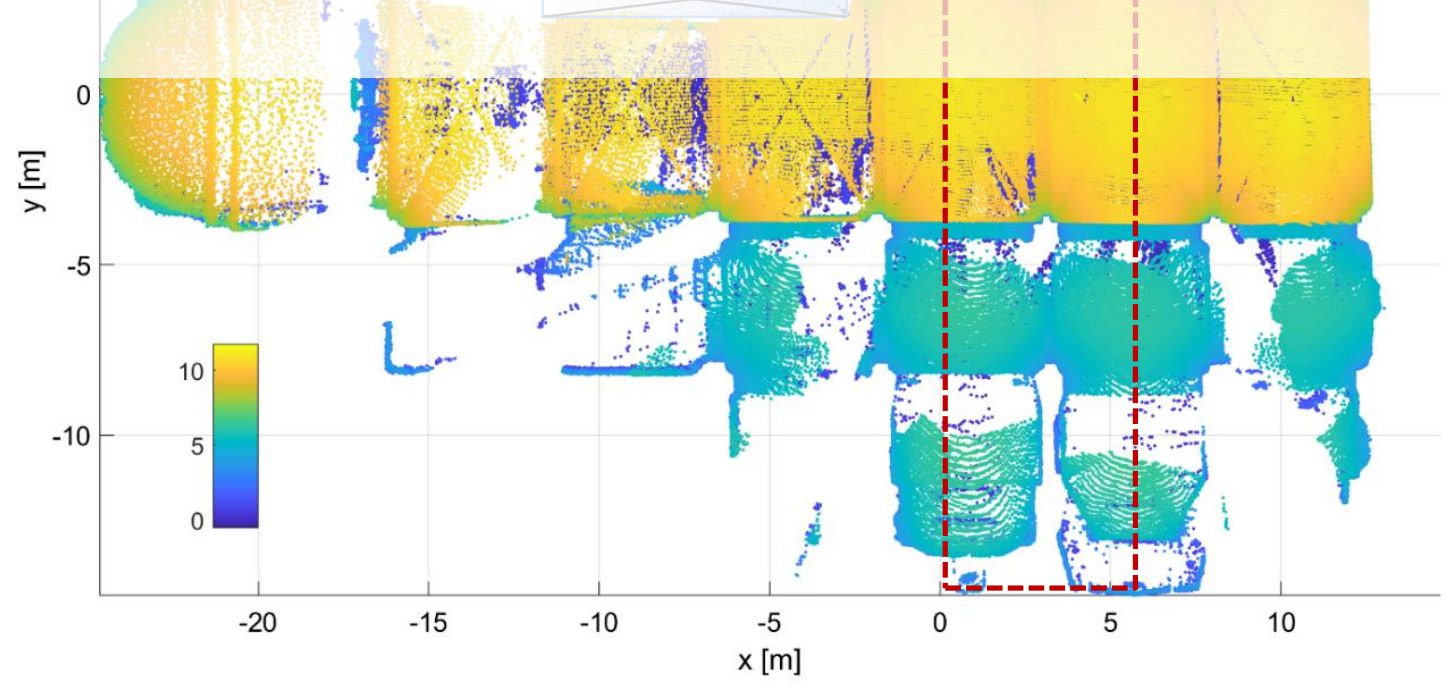

Figure 3: Point cloud measurement of the interior of the church of St. Bassiano. 
The survey was focused on the first 3 spans of the church, starting from the facade. It considered a continuous path along the central nave, from which only 12 scans out of 150 where extracted and used to create the final point cloud. The initial alignment was based on the data provided by the Inertial Measurement Unit. A second alignment step was carried out by using the Iterative Closed Point algorithm (ICP) [11]. The final point cloud includes 1 million points and an alignment error of $0.02 \mathrm{~m}$ (Fig. 2 - 3). The southern part (comprising a part of the nave and aisle) could not be surveyed due to a scaffold present for cleaning paintings.

\subsection{Historical notes on the structural evolution}

The structural evolution of the church of St. Bassiano is closely connected with historic events between the $15^{\text {th }}$ and $19^{\text {th }}$ centuries, when it was object of many interventions [12]. In the $14^{\text {th }}$ century, Pizzighettone become part of the Milanese domain under the Visconti first and then the Sforza family, who built the masonry town walls [13]. In the beginning of the $16^{\text {th }}$ century, the walled town was invaded by the French and then by the Spanish. In the $18^{\text {th }}$ and $19^{\text {th }}$ centuries the town was gained by the Austrians, and in between by Napoleon's troops, until the unification of Italy in 1861. The following phases can be determined (Fig. 4):

1) The reconstruction of a pre-existing church starting from 1158 and dedicated to Saint Bassiano. The building probably already had three naves and two towers at the place of the two lateral apses.

2) In medieval time cross masonry vaults were added over the three naves and the façade

was elevated to cover the increased height of the central nave.
3) In 1456 the Milanese Sforza family radically transformed. church: the façade was Two rows of chapels Northward the nave and the chapels with only
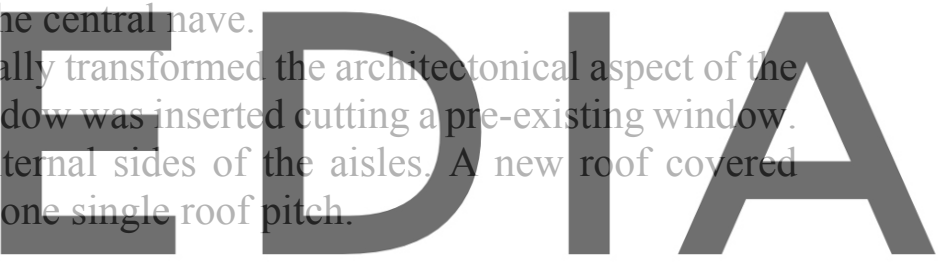

Register for free at https//www.scipedia.com to download the version without the watermark
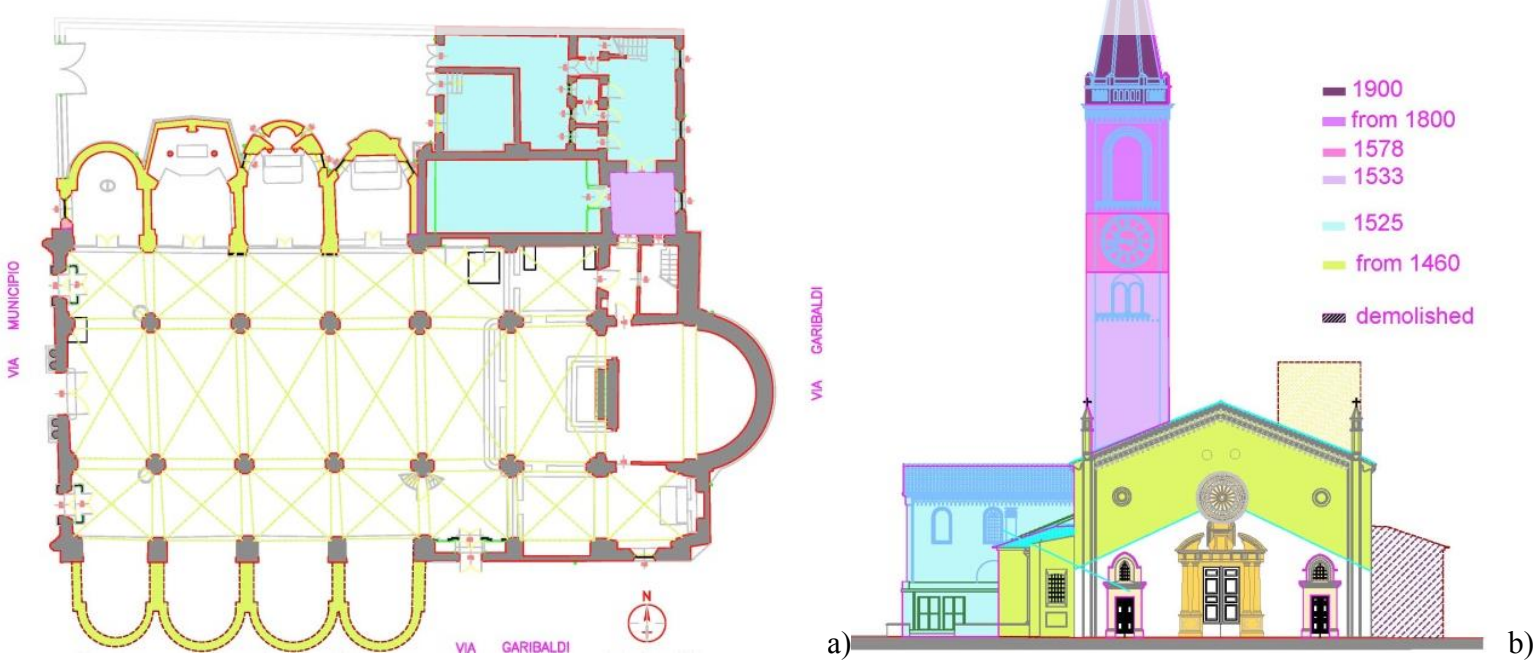

Figure 4: Historical evolution of the St. Bassiano church: a) plan and b) West facade view [12]. 
4) In late Renaissance time, between 1525 and 1580, additional changes occurred: a) in 1525 the present sacristy was added North-West of the church; in 1533 the bell tower was moved from the South to the North side of the apse and the first part of the present tower was built (Fig. 4); In 1578 the first elevation of the bellfry took place to add a clock.

5 ) In the $18^{\text {th }}$ century the elevation of the old bellfry on the South side was demolished and the entrance portal probably was added at that time.

6) In the $19^{\text {th }}$ century the facing South chapels were demolished, probably due to the need to widen the adjacent roadway. At this time, iron tie rods were added to the masonry vaults. In 1820 the bellfry on the North side was further elevated and in 1835 the internal church was fully decorated with the present visible style.

7) In the early $20^{\text {th }}$ century the last elevation of the bellfry with octagonal shape was added. In 1963 a restoration made by the architect A. Edallo, changed the roof, partially also with modern reinforced concrete beams and the long single pitch Northward was demolished. Two chapels on the North side were rebuilt in modern style.

\subsection{Description of the structural conditions}

The crack pattern survey highlighted the serious damage both in the vertical and horizontal structures, weakened by the continuous transformations over the centuries. Almost continuous lines of cracks can be observed in the longitudinal direction along the nave and aisles starting close to the façade and reaching the apse (Fig. 5). Past interventions, supporting directly the roof over the vault, bur and causing many struc also along the chapels main nave in South-East direction.

The belfry has a poor foundation (in the 1
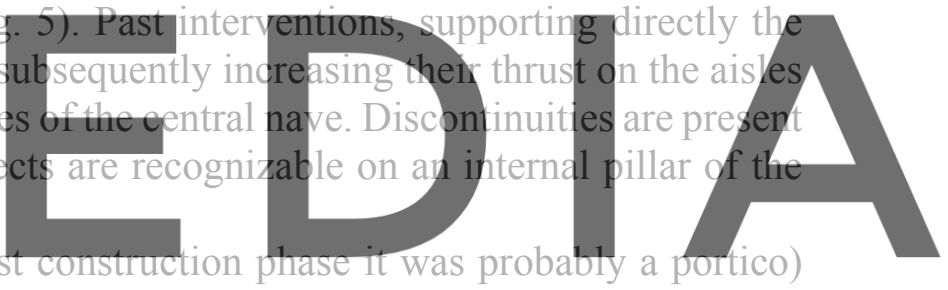
which caused a relevant out of plumb of about $12 \mathrm{~cm}$ towards the North-East side, with resultant

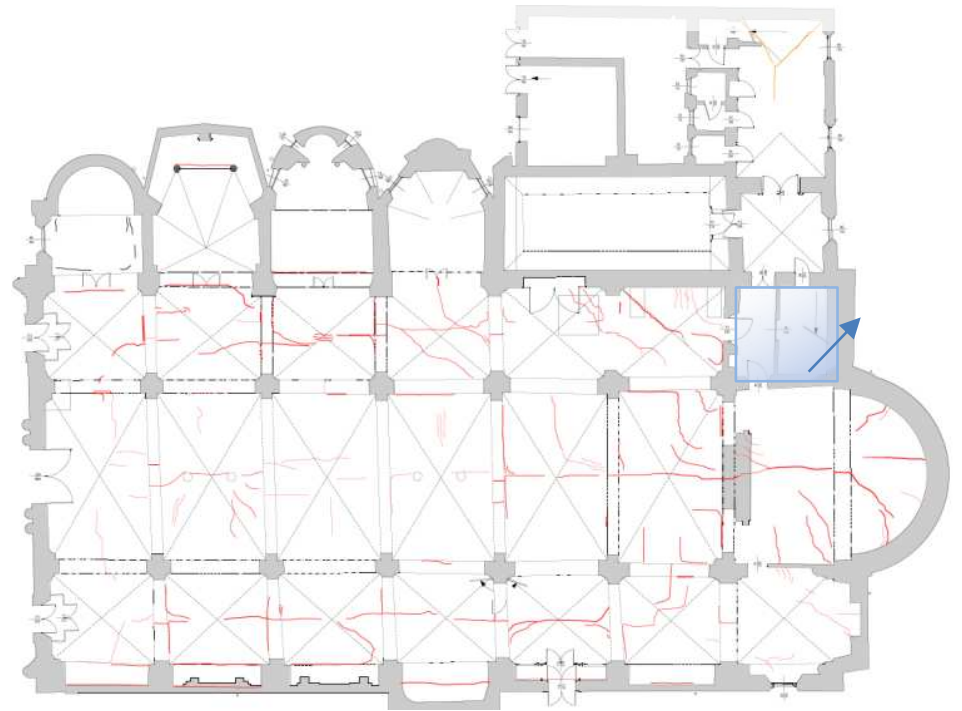

Figure 5: Crack pattern survey of the vaults of St. Bassiano church as of today, and bellfry out of plumb. 
The severe structural damage and the needs to replace the damaged roof led then in 2013 to a new general structural strengthening intervention [12] that required the closing of the town church for many years.

The intervention was divided in different phases: the first phase included the complete substitution of the main nave roof from the façade to the apse, with a new timber structure not loading the vaults anymore and with timber trusses, removing the horizontal thrust on the bearing walls. Such intervention stopped the main damage cause affecting the apse, the cross vaults and the main masonry arches of the nave, which were consolidated with FRCM (Fiber Reinforced Cementitious Matrix) composite system, made with a bidirectional mesh of Polybenzoxazole (PBO) fibers [12].

The first phase was considered urgent, allowing the temporary reopening of the church at the end of this step; a second and a third phases (dealing with the aisles, the towers and foundations) were postponed to find the necessary funds and to conclude the works; these at present still need to be executed.

\section{STRUCTURAL MODEL}

\subsection{FE model geometry and meshing}

The geometry of the FE model is based on LiDAR scanning of the church interior (see section 2.2). Although, the geometry is based on the scanning of the $2^{\text {nd }}$ bay, the considered as representative of the typical bay.

The FE model includes appro linear tetrahedral elennents.
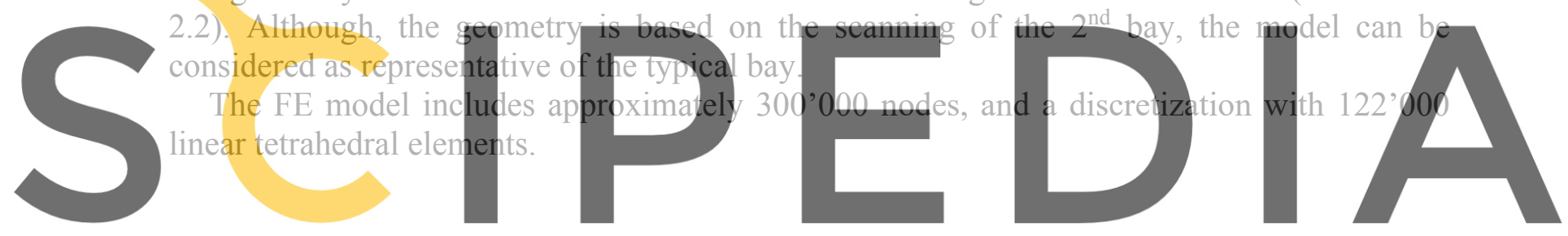

Register for free at https//www.scipedia.com to download the version without the watermark

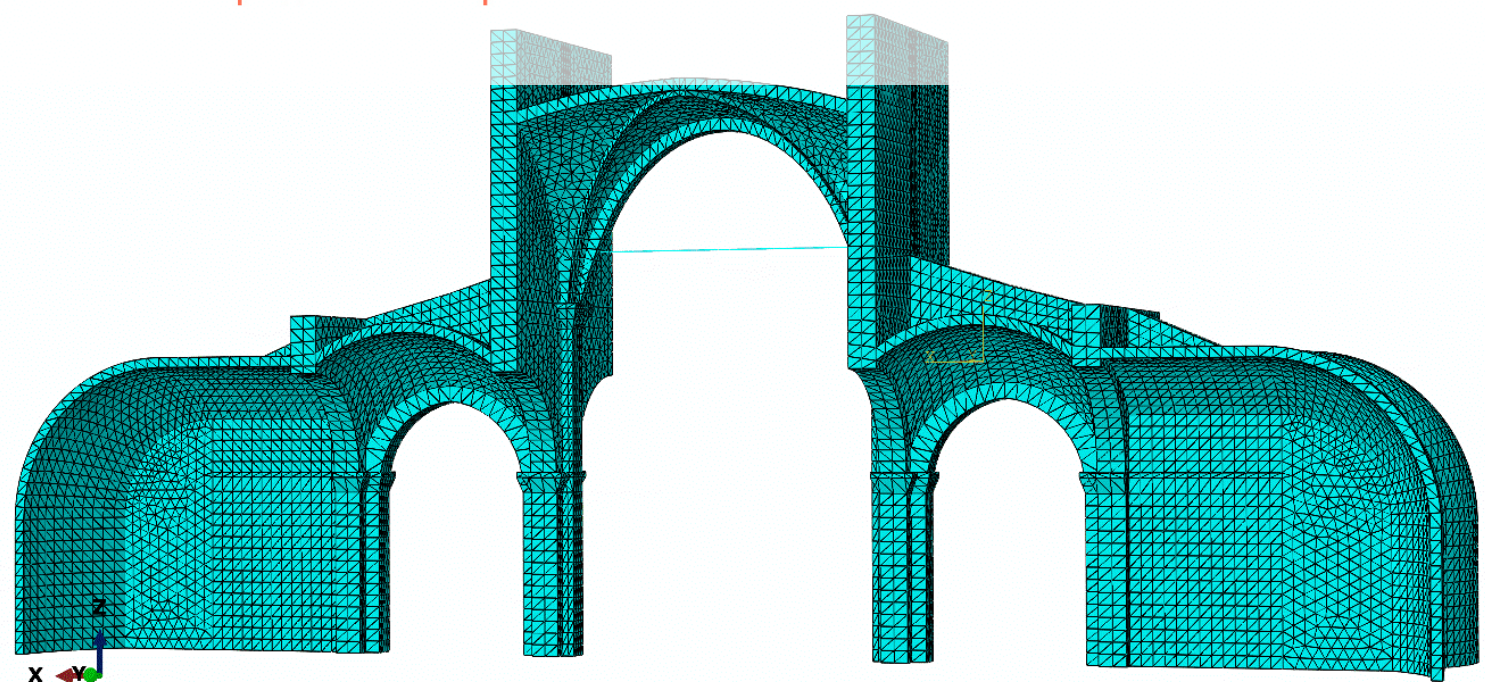

Figure 6: View of St. Bassiano discretized FE model, including also the removed southern chapels 
The model considers a parametric geometric modelling procedure, for the vault in the central nave which is the most complex parts of the system[5]. It considers the tas-de-charge, ribs, arches, and the vault surcharge [14]. The rest of the structural members (the piers, the buttresses, the walls, and iron tie rods) are modelled manually in Abaqus CAE environment ([15]). The important details of the geometry such as the curvature of the arches, ribs, vault web and characteristics of the geometric rules adopted during the construction are identified.

Finally, the numerical model considers also the southern chapels, removed in the $19^{\text {th }}$ century. This component of the structural system is necessary as an input for the sequential analysis. The geometry of the southern chapel is assumed to be like the one of the northern sides, since no data are available in the moment.

\subsection{Constitutive model and material properties}

The masonry is modelled with a non-linear plastic damage constitutive model according to the description of Lee and Fenves [16]. The damage variables in tension $d t$ and in compression $d c$ are taken into consideration by eq. 1 and eq. 2 :

$$
\sigma_{t}=\left(1-d_{t}\right) E_{0}\left(\varepsilon_{t}-\varepsilon_{t}^{p l}\right) ; \sigma_{c}=\left(1-d_{c}\right) E_{0}\left(\varepsilon_{c}-\varepsilon_{c}^{p l}\right)
$$

where: $\sigma_{t}\left(\sigma_{c}\right)$ is the mono-axial tensile (compressive) stress,
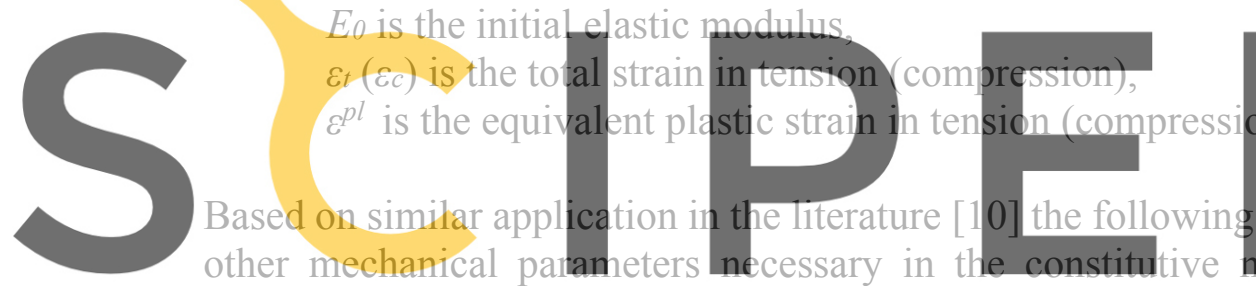

Based on similar application in the literature [10] the follow
other mechanical parameters necessary in the constitutiv
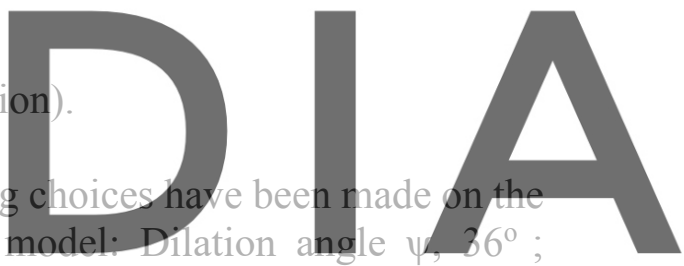

eccentricity 0.1 ; the ratio of biaxial to uniaxial compression yield strength $f_{b 0} / f_{c 0}, 1.16$; the

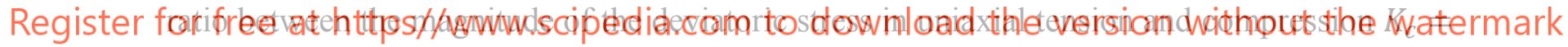

0.667 and viscosity parameter is kept at a low level, 0.0002. The data regarding the stress-

strain curve are reported in table 1. In the present analysis only one masonry typology is considered. The selected mechanical parameters are chosen based on similar masonry typologies (see table C8A.2.1.in [17]). Although, it is possible to consider more typologies, this could be misleading considering the current level of knowledge. A different choice is clearly made for the rubble fill in the masonry vaults, where the mechanical properties are clearly lower compared to the rest of the structure (Table 1).

Table 1: Mechanical material properties adopted for the numerical analysis.

\begin{tabular}{cccccccc}
\hline Properties & $\gamma$ & $\mathrm{E}$ & $\vartheta$ & $\mathrm{f}_{\mathrm{c}}$ & $\mathrm{f}_{\mathrm{t}}$ & $\mathrm{G}_{\mathrm{f}}^{\mathrm{I}}$ & $\mathrm{G}_{\mathrm{fci}}$ \\
Type & {$\left[\frac{\mathrm{kN}}{\mathrm{m}^{3}}\right]$} & {$\left[\frac{\mathrm{N}}{\mathrm{mm}^{2}}\right]$} & {$[-]$} & {$\left[\frac{\mathrm{N}}{\mathrm{mm}^{2}}\right]$} & {$\left[\frac{\mathrm{N}}{\mathrm{mm}^{2}}\right]$} & {$\left[\frac{\mathrm{Nmm}}{\mathrm{mm}^{2}}\right]\left[\frac{\mathrm{Nmm}}{\mathrm{mm}^{2}}\right]$} \\
\hline Brick masonry & 18 & 2000 & 0.2 & 4 & 0.2 & 0.012 & 1.2 \\
\hline Rubble fill masonry & 16 & 800 & 0.2 & 2 & 0.15 & 0.012 & 0.5 \\
\hline Steel & 79 & $2 \cdot 10^{5}$ & 0.3 & - & - & - & - \\
\hline
\end{tabular}




\subsection{Staged construction analysis}

The structural analysis considers a sequential analysis focusing on the interventions in the $19^{\text {th }}$ century where the southern chapels were removed, and the central nave was reinforced with iron ties to contain its horizontal thrust, with average cross section 3,4 x $6 \mathrm{~cm}$. Moreover, as suggested by Angjeliu, et al. [10] also the construction phase of the central nave has been included in order to have an improved prediction of the axial force in the iron ties. The considered stages can be described as follows:

Stage 1: Construction of the aisle and chapels (fig. 7a),

Stage 2: Construction of the central nave (fig. $7 b$ ),

Stage 3: Removal of the southern chapel and addition of the iron ties in the nave (fig. 7c).

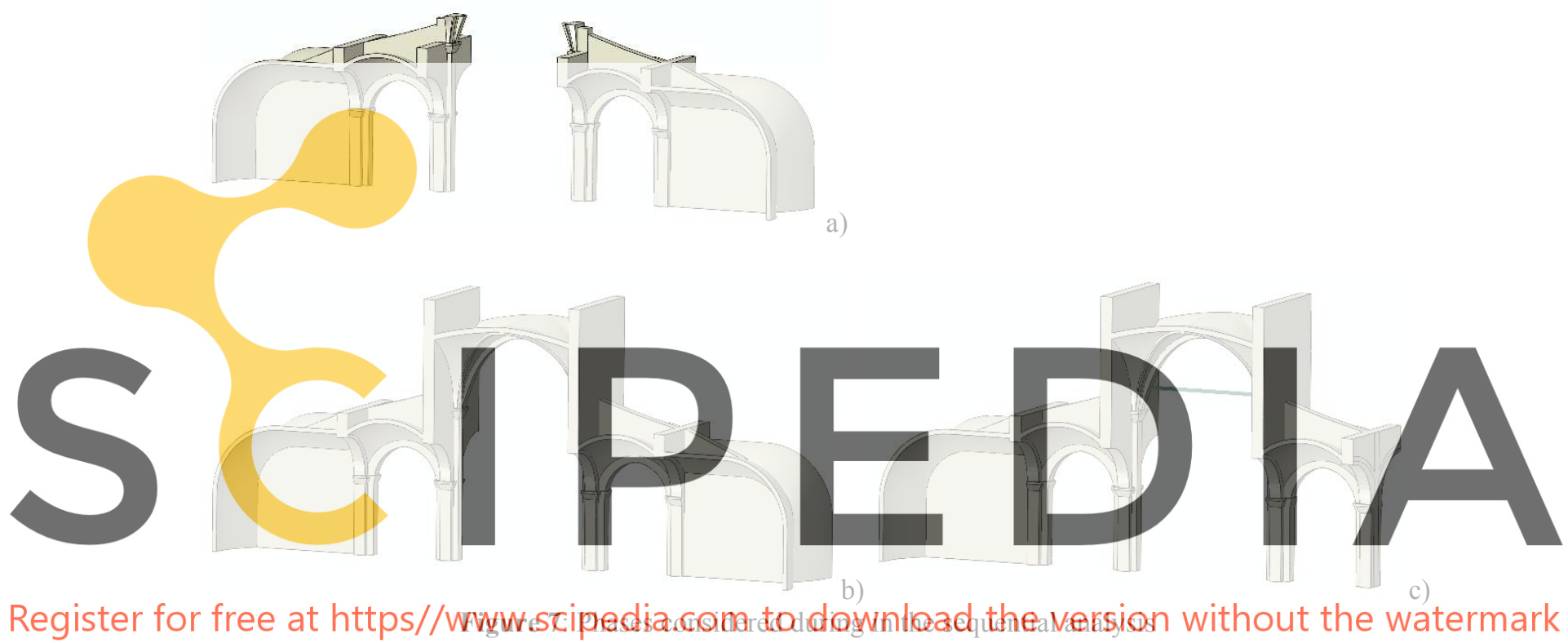

\section{RESULTS}

In this section the results focus on the interpretation of the observed damage in relation to the documented structural evolution in time of the church of St. Bassiano. In particular, the removal of the southern chapels and the addition of iron tie rods in the central nave changed significantly the structural response.

\subsection{Self-weight analysis}

The maximal vertical stresses (S33) due to self-weight in the original configuration is approximately $0.79 \mathrm{MPa}$. These are average values but also typical in masonry constructions. The change of the structural system with the insertion of the steel ties and the removal of the chapels with a buttress role has a significant effect to self-weight vertical stresses which double to $1.76 \mathrm{MPa}$ (Fig. 8).

In particular the results show that the removal of the southern chapel gives rise to damage propagation in the aisle vaults and walls over the arch (Fig. 9). Therefore, the crack in the aisle vaults documented in the recent crack pattern, can be connected clearly with the removal of the 
southern chapels in the $19^{\text {th }}$ century (Fig. 5). The inserted iron tie, which in this stage is around $47 \mathrm{kN}$, is not enough to completely replace the buttressing effect of the previous chapels.
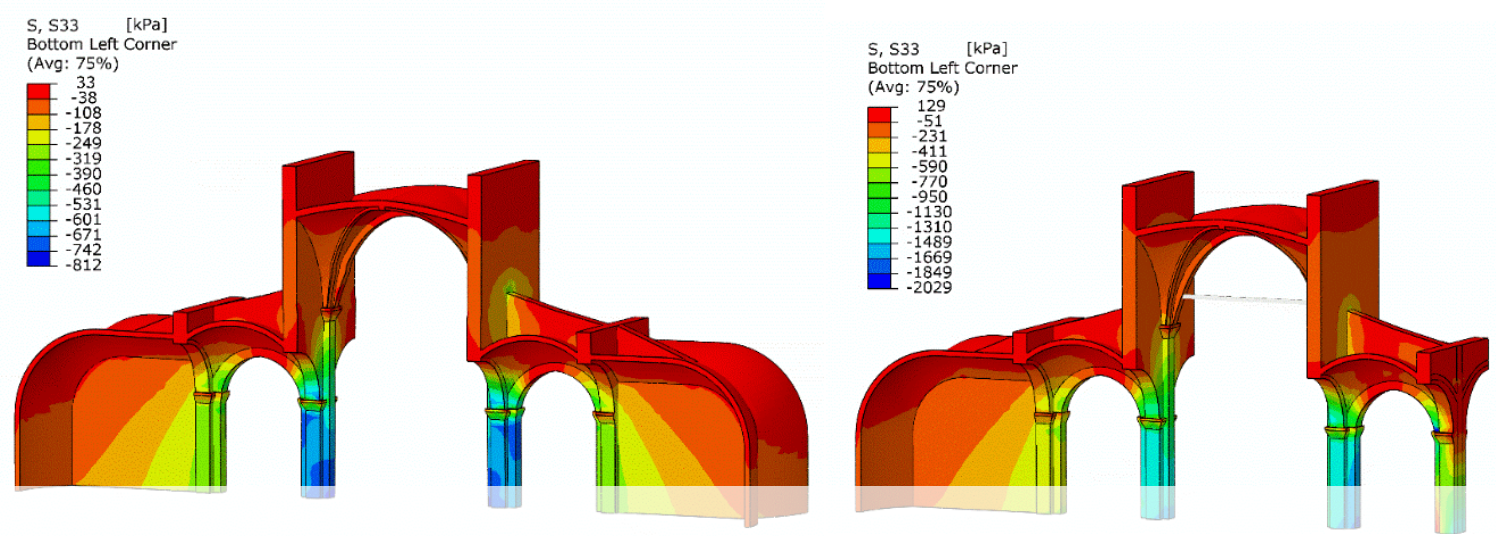

Figure 8: Vertical stresses S33 due to self-weight: a) original configuration, b) current configuration.
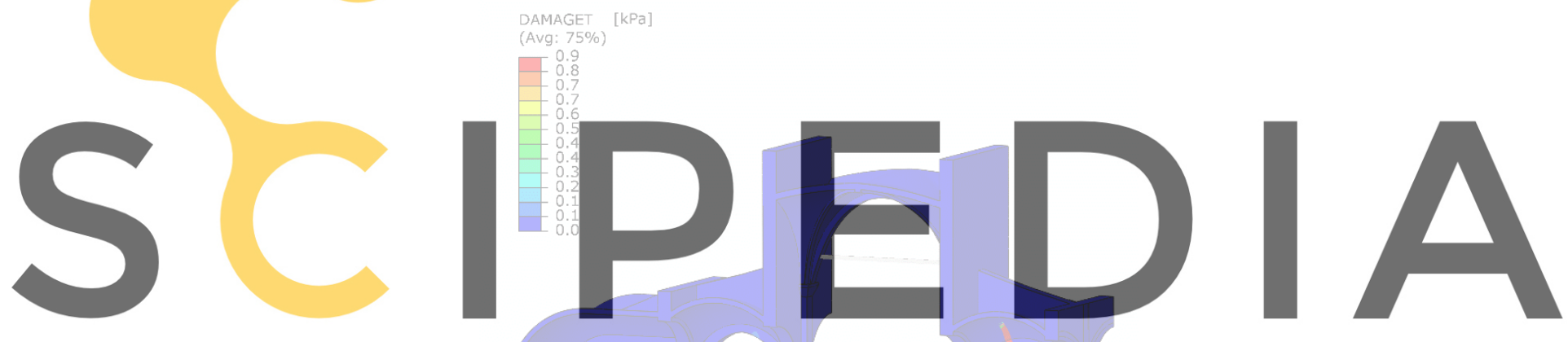

Register for free at https//www.scipedia.com to download the version without the watermark

Figure 9: Damage in the southern aisle due to the removal of the chapel in the current configuration

\subsection{Settlement analysis}

As widely studied in the literature, the soil settlements have a significant effects on damage in historic masonry buildings [18]. In the case of St. Bassiano church, beside the certainty on the presence of soil settlements, there was no information on their specific effects. A set of analysis, considering vertical settlements of $2 \mathrm{~cm}$ were used to quantify soil settlements effects on the crack pattern. A comparison of the results (Fig. 10) with the observed crack pattern is useful to understand the settlements which actually happened. The preliminary results show that soil settlements in the $2^{\text {nd }}$ and $4^{\text {th }}$ line of piers give a good match between the simulations and the survey crack pattern (Fig. 5). Moreover, the settlements of the $4^{\text {th }}$ line of supports find further confirmation in the values of tension force in the iron ties (see next section $4.3)$. 

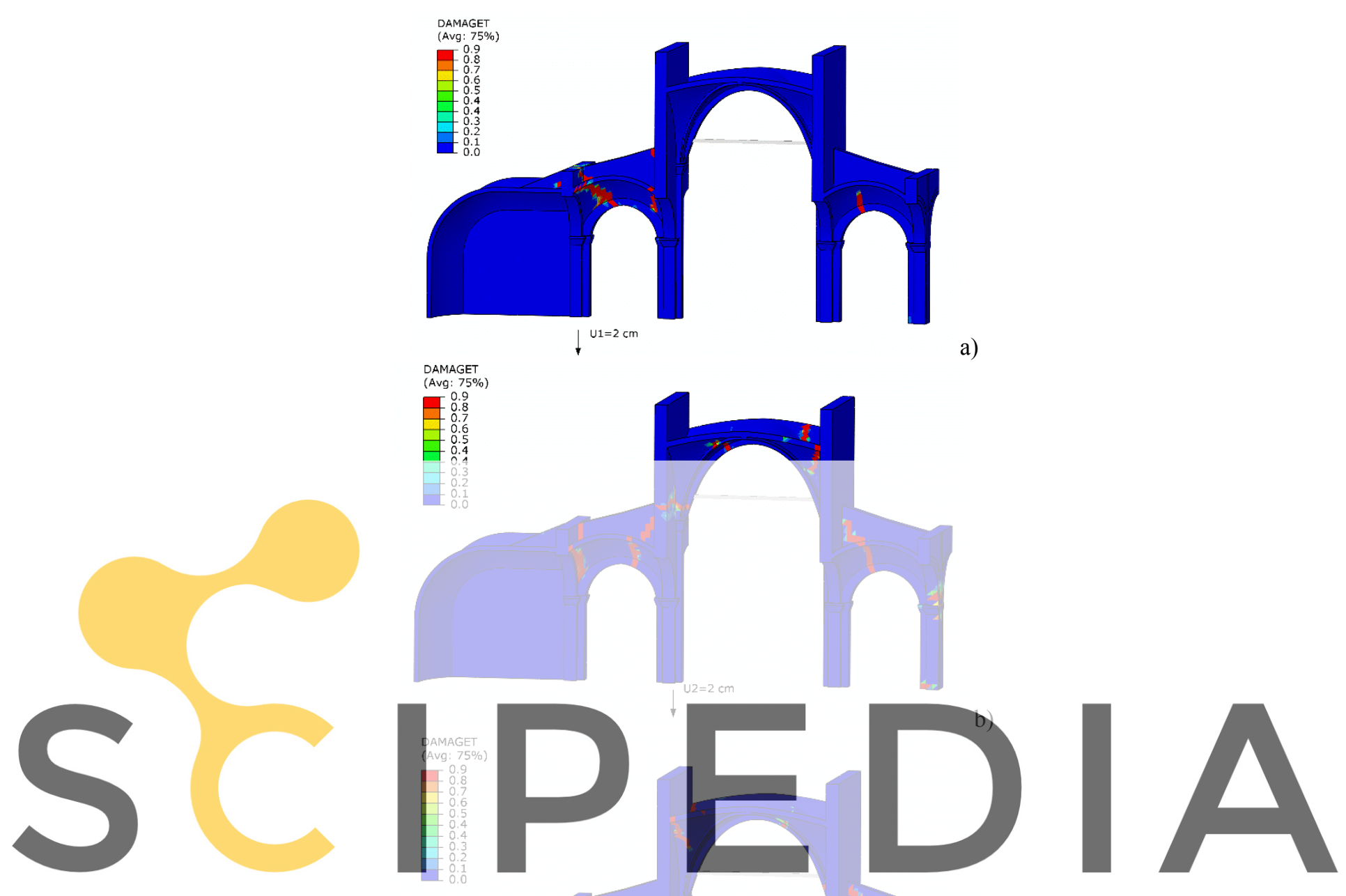

Register for free at https//www.scipedia.com to download the version without the watermark
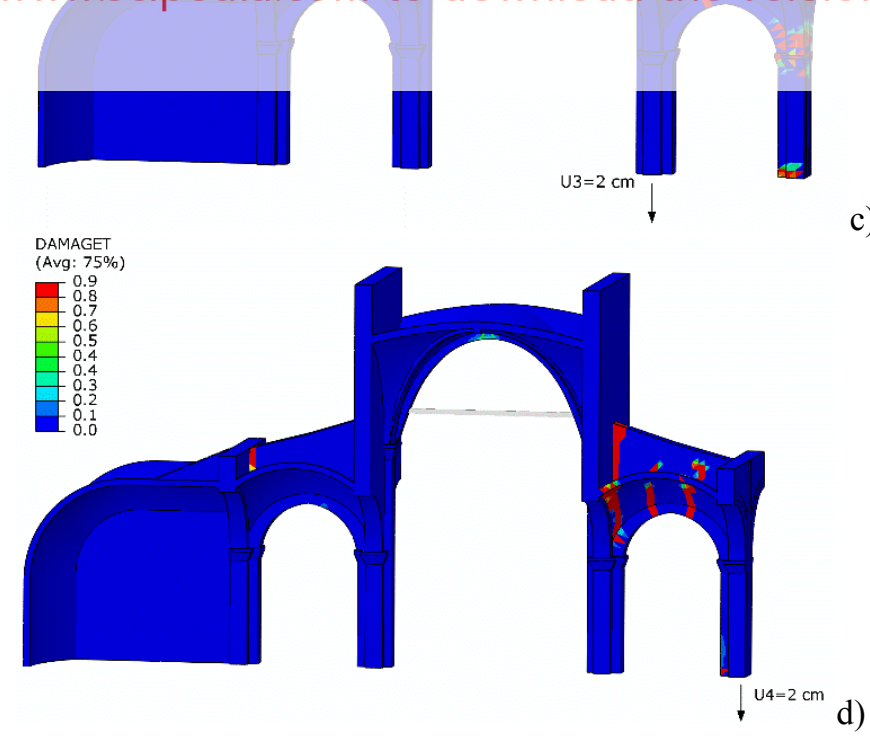

Figure 10: Damage simulation in the current configuration due to settlements a) $1^{\text {st }}$, b) $2^{\text {nd }}$, c) $3^{\text {rd }}$, d) $4^{\text {th }}$ support. 


\subsection{Analysis of the tension in the iron tie rods}

The tension force in the iron tie rods, measured experimentally during a previous diagnostic campaign [12] is used here in combination of the numerical model to understand the effects of the settlements (Fig. 11). The tension force in the iron tie rods from the self-weight is $46.9 \mathrm{kN}$, which is far from the experimental values, denoting the possibility of settlement effects (as seen in the crack pattern).

The settlements effects produce tension force values in the range $22 \mathrm{kN}-97 \mathrm{kN}$. In particular the three supports $1-3$ contribute to lowering the tension tie force. An exception here is only in the $4^{\text {th }}$ support (southern pier) settlement, which doubles the axial force up to $97 \mathrm{kN}$. This value is particularly close to experimental measurements in the $1^{\text {st }}$ and $3^{\text {rd }}$ bay, which indicates the settlement of the $4^{\text {th }}$ support gives an important contribution in the damage pattern and the tension value in iron ties. Further analysis of these results should allow to understand a more detailed view of the actual combination.

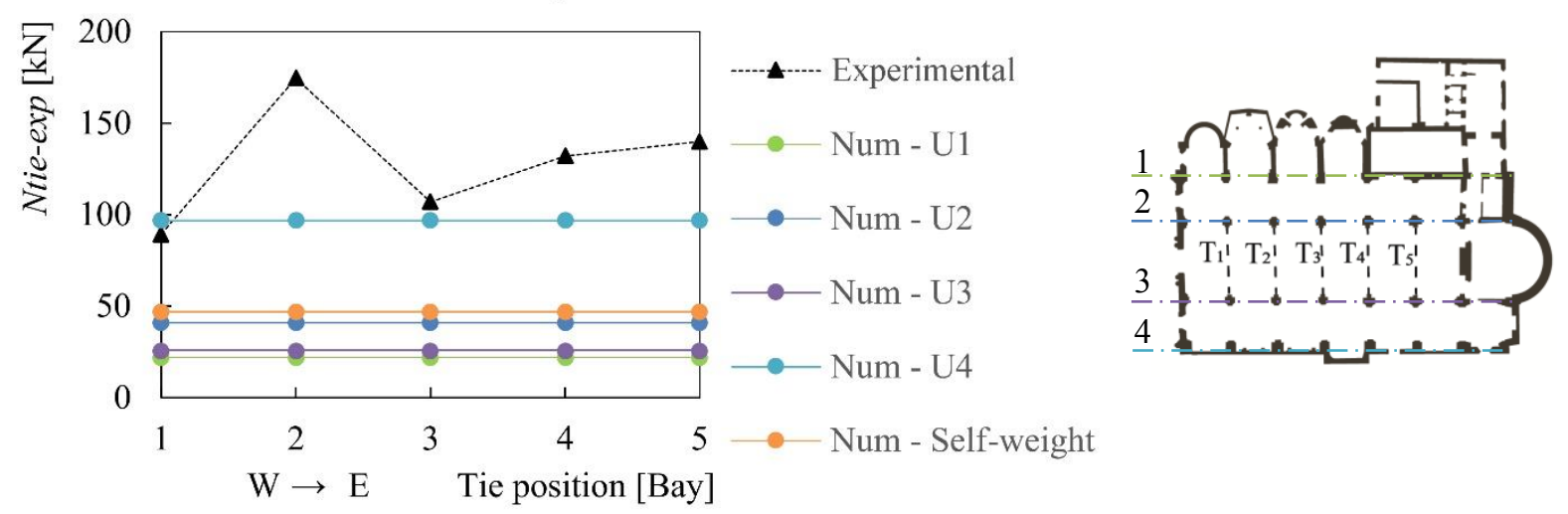

Figure 11: Measurements of the iron tie axial force and the iron tie rod position in plan.

\section{CONCLUSIONS}

In the present paper the study of the structural damage in relation to construction phases and to soil settlements has been presented. The church of St. Bassiano which has been used as case study features many transformations in the past centuries. This makes it a perfect case to study these phenomena and observations. The conclusions of present study are:

- the importance of the geometry and the survey with LiDAR scanning in the creation of realistic FE structural models;

- the clear connection of the observed damage with the removal of the southern chapels;

- the crack pattern is related to a combination of settlements, where the one affecting the southern pier is particularly important since it produces damage similar to the present crack pattern; this result is relevant for the strengthening intervention - de facto one of the future restoration phases will improve the foundations by underpinning.

- the possibility to interpret the measured tie tension as a combination of settlement effects.

Further work could consider: LiDAR scanning of the exterior and updating the FE model accordingly; extraction of structural deformations from the point cloud, calibration and refinement of material properties and a detailed study of the soil settlement effect combination. 


\section{Acknowledgements}

The authors are grateful to Ouster Inc. who supported our research work by donating a Lidar sensor, used during geometric survey in the church of St. Bassiano. We also thank the Rev. Andrea Bastoni, the Rev. Andrea Lamperti Tornaghi and Eng. Gian Ermes Massetti for the access, help, diagnostic data and support during the study of the church of St. Bassiano in Pizzighettone (Cremona).

\section{REFERENCES}

[1] H. Stovel, Origins and influence of the Nara document on authenticity, APT Bulletin 39 (2/3) (2008)

[2] S. Saloustros, L. Pelà, P. Roca, J. Portal, Numerical analysis of structural damage in the church of the Poblet Monastery, Engineering Failure Analysis 48 (2015) 41-61,

[3] P. Roca, M. Cervera, G. Gariup, L. Pela', Structural Analysis of Masonry Historical Constructions. Classical and Advanced Approaches, Archives of Computational Methods in Engineering 17 (3) (2010) 299-325, doi:https://doi.org/10.1007/s11831-010-9046-1.

[4] H. Macher, T. Landes, P. Grussenmeyer, From Point Clouds to Building Information Models: 3D SemiAutomatic Reconstruction of Indoors of Existing Buildings, Applied Sciences 7 (10) (2017) 1030

[5] G. Angjeliu, G. Cardani, D. Coronelli, A parametric model for ribbed masonry vaults, Automation in Construction 105 (2019) 102785, doi:https://doi.org/10.1016/j.autcon.2019.03.006.

[6] S. Havemann, D.W. Fellner, Generative mesh modeling, University of Braunschweig-Institute of Technology, 2005.

[7] G. Angjeliu, D. Coronelli, G. Cardani, Challenges in Modelling Complex Geometry in Historical Buildings for Numerical Simulations, Proc. The 18th International Conference on Geometry and Graphics, Vol. 809, Springer, Milan, Italy, 2019, pp. 1218-1230

[8] A. Taliercio, L. Binda, The Basilica of San Vitale in Ravenna: Investigation on the current structural faults and their mid-term evolution, Journal of Cultural Heritage 8 (2) (2007) 99-118,

[9] P. Roca, M. Cervera, L. Pelà, R. Clemente, M. Chiumenti, Continuum FE models for the analysis of Mallorca Cathedral, Engineering Structures 46 (2013) 653-670,

[10] G. Angjeliu, D. Coronelli, G. Cardani, T. Boothby, Structural assessment of iron tie rods based on numerical modelling and experimental observations in Milan Cathedral, Engineering Structures 206 (2020) 109690, doi:https://doi.org/10.1016/j.engstruct.2019.109690.

[11] P. Glira, N. Pfeifer, C. Briese, C. Ressl, A Correspondence Framework for ALS Strip Adjustments based on Variants of the ICP Algorithm, Photogrammetrie - Fernerkundung - Geoinformation 2015 (4) (2015) 275-289, doi:10.1127/pfg/2015/0270.

[12] G. Cardani, G.E. Massetti, When the strengthening of historic masonry buildings should be carried out in different phases: the structural reinforcement and monitoring of the Lombard-Romanesque church of Saint Bassiano, in Pizzighettone (CR), Italy, Proc. PROHITEC'17-3rd International Conference on Protection of Historical Constructions, IST Press, Lisbon, 2017, pp. 1-12, isbn:9898481587.

[13] G. Cardani, R. Pizzoli, The town walls of Pizzighettone: A fortified settlement crossed by a river, through six centuries of history, Sustainable Mediterranean Construction (1) (2019),

[14] G. Angjeliu, G. Cardani, D. Coronelli, Digital Modelling and Analysis of Masonry Vaults, ISPRS International Archives of the Photogrammetry, Remote Sensing and Spatial Information Sciences XLII2/W11 (2019) 83-89, doi:https://doi.org/10.5194/isprs-archives-XLII-2-W11-83-2019.

[15] Hibbitt, Karlsson, Sorensen, ABAQUS Manual, Dassault Systèmes, 2016.

[16] J.H. Lee, G.L. Fenves, Plastic-damage model for cyclic loading of concrete structures, Journal of Engineering Mechanics-Asce 124 (8) (1998) 892-900,

[17] C.S. Ministero delle Infrastrutture d dei Trasporti, Circolare 2 febbraio 2009, n. 617-Istruzioni per l'applicazione delle "Nuove norme tecniche per le costruzioni" di cui al DM 14 gennaio 2008, Gazzetta Ufficiale, 2009.

[18] G. Cardani, D. Coronelli, G. Angjeliu, Damage observation and settlement mechanisms in the naves of the Cathedral of Milan, Proc. Structural Analysis of Historical Constructions (SAHC) Leuven, Belgium, 2016. 